\title{
Políticas públicas e qualificação profissional em turismo: uma análise das metodologias de pesquisa
}

\author{
Public policies and professional qualification in tourism: an analysis of research \\ methodologies
}
Políticas públicas y calificación profesional en turismo: un análisis de las metodologías de investigación

Ivan Conceição Martins da Silva ${ }^{1}$

Este artigo foi recebido em 28 de dezembro de 2019 e aprovado em 29 de junho de 2020

\begin{abstract}
Resumo: A qualificação profissional vem caracterizando-se como objeto de crescente interesse para as políticas públicas, ganhando também atenção das pesquisas acadêmicas no campo do turismo. Assim, o objetivo deste trabalho é analisar metodologias utilizadas em pesquisas nos campos de estudo das políticas públicas de qualificação profissional e da qualificação profissional em turismo. A metodologia utilizada baseou-se em uma revisão integrativa de literatura acerca dos campos de estudo mencionados, com levantamento bibliográfico nas bases de dados Scopus, Web of Science, Scielo, Spell, Redalyc e Google Acadêmico. Foram analisados 45 trabalhos e identificados 20 procedimentos metodológicos de pesquisa. As pesquisas contribuem para construção de um histórico das políticas da área e um panorama da diversidade de programas nas regiões brasileiras, todavia a produção é insuficiente sobre avaliação dos resultados dos programas e sobre as ações de qualificação em turismo. Como resultado da análise das metodologias, averiguou-se que parte das pesquisas visava debates mais teóricos e conceituais; parte debruçou-se sobre dados e documentos; e parte analisou a execução prática do fenômeno. Quanto às contribuições para o tema "Políticas públicas de qualificação profissional em turismo", apreendeu-se ainda que a escolha na dimensão de qualificação que será abordada (educação/trabalho/política) possui influência na escolha da metodologia da pesquisa.
\end{abstract}

Palavras-chave: Metodologias de pesquisa. Políticas públicas. Qualificação profissional. Turismo.

\begin{abstract}
Professional qualification became an object of increscent attention for public policy in tourism, also getting attention of academic researches of the area. Therefore, this paper's aim is analyzing the methodologies utilized in researches of professional qualification's public policy and professional qualification in tourism. For this, the methodology used was a literature's integrative review about the mentioned fields research. The bibliographic survey was from six data bases: Scopus, Web of Science, Scielo, Spell, Redalyc and Google Scholar. 45 researches were analyzed, and 20 methodological procedures were identified. The papers contribute a lot to the construction of a qualification policy history and a panorama of programs from several Brazilian regions; however, the academic production is insufficient about programs results evaluation and programs of qualification in tourism. As a result from methodologies analysis, it was verify that part of the papers aimed theoretical and conceptual debates; part focused in data and documents; and part analyzed the phenomenon's practical execution. About the contributions for the theme "public policies of professional qualification in tourism" it was apprehended that the choice on which qualification dimension will be approach (education/labor/politic) can also interfere in the methodology's choice.
\end{abstract}

Key words: Research methodologies. Public policies. Professional qualification. Tourism.

Resumen: La calificación profesional se ha caracterizado como un objeto de creciente interés para las políticas públicas y también ha atraído la atención de la investigación académica en el campo del turismo. Por lo tanto, el objetivo de este trabajo es analizar las metodologías utilizadas en la investigación en los campos de estudio de las políticas públicas de calificación profesional y calificación profesional en turismo. La metodología utilizada se basó en una revisión bibliográfica integradora sobre los campos de estudio mencionados, con una encuesta bibliográfica en las bases de datos Scopus, Web of Science, Scielo, Spell, Redalyc y Google Scholar. Analizamos 45 artículos e identificamos 20 procedimientos metodológicos de investigación. Las investigaciones contribuyen a la construcción de una historia de las políticas del área y una visión general de la diversidad de programas en

${ }^{1}$ Formação/curso: Mestre em Turismo. Instituição: Membro do grupo de pesquisa "Turismo, gestão e territórios" da Universidade Federal Fluminense. - UFF, Niterói - RJ, Brasil. E-mail: ivanmartins@id.uff.br 


\section{POLÍTICAS PÚBLICAS E QUALIFICAÇÃO \\ PROFISSIONAL: UMA ANÁLISE DAS \\ METODOLOGIAS DE PESQUISA}

las regiones brasileñas, sin embargo, no hay producción suficiente en la evaluación de los resultados del programa y en las acciones de calificación turística. Como resultado del análisis de las metodologías se encontró que parte de la investigación apuntaba a debates más teóricos y conceptuales; parte es dirigida a datos y documentos; y parte analizó la ejecución práctica del fenómeno. En cuanto a las contribuciones al tema "políticas públicas de calificación profesional en turismo", también se apreció que la elección en la dimensión de calificación que se abordará (educación / trabajo / política) influye en la elección de la metodología de investigación.

Palabras Clave: Metodologías de investigación. Políticas públicas. Calificación profesional. Turismo.

\section{Introdução}

O desenvolvimento da qualificação profissional, como um processo de destaque para a sociedade, pode ser rastreado, no Brasil, desde meados do século XIX, por conta de processos de urbanização da época (OLIVEIRA, 2013). Após a Segunda Guerra Mundial, a qualificação foi tomando novos contornos, a partir da Europa (MONTALVÃO, 2015). Pass a ser, então, progressivamente, um objeto de ação do Estado até que se institucionalize como um importante eixo de políticas públicas no Brasil. No nível federal, é possível destacar, considerando apenas as pastas de Educação e Trabalho, pelo menos cinco políticas públicas de grandes proporções desde a década de 1960.

Inicialmente, o setor do turismo figurava apenas como um eixo nessas políticas de abrangência geral $^{2}$. Com a instituição do Ministério do Turismo (MTur) em 2003, o setor passou a receber também políticas públicas de qualificação especificamente para o turismo ${ }^{3}$. O primeiro Plano Nacional de Turismo (PNT) do MTur já incluía a qualificação profissional em um de seus macroprogramas, embora de forma incipiente (MTur, 2003). O plano seguinte - PNT 2007-2010 - possibilitou a qualificação com programas específicos e locais (MTur, 2007). O PNT 2013-2017 ampliou o alcance do Ministério, instituindo um programa nacional para a qualificação profissional, o Pronatec Turismo (MTur, 2013). E a partir de 2015, o MTur passou a realizar pesquisas e publicar novos documentos - como as Diretrizes Nacionais para Qualificação Profissional em Turismo (DNQT) e a Política Nacional de Qualificação Profissional em Turismo (PNQT).

A absorção desses dois temas pelas publicações científicas apresenta diferentes panoramas. Por um lado, a área das políticas públicas de qualificação (em geral) apresenta muitos trabalhos, que analisam em profundidade programas ou políticas de nível federal e estadual, além de tecer perspectivas históricas e comparativas entre eles (BULHÕES, 2004; FERREIRA, 2013; CACIOLATO; GARCIA, 2014; MONTALVÃO, 2015; NASCIMENTO, 2015; CORCETTI; LORETO, 2017). Por outro, a área

\footnotetext{
${ }^{2}$ Até os dias de hoje, muitas ações de qualificação e educação profissional, tanto do governo federal quanto de governos estaduais, possuem o eixo 'Turismo, hospitalidade e lazer'.

${ }^{3}$ De acordo com Velasco González (2011), políticas públicas de turismo podem ser compostas por seis tipos de instrumentos: organizativos, programáticos, normativos, financeiros, de investigação e de comunicação. Nesse sentido, destaca-se como política pública de turismo para qualificação profissional as ações do MTur (instrumento organizativo) expressas por seus planos, programas e políticas (instrumentos programáticos).
}

Observatório de Inovação do Turismo - Revista Acadêmica

Vol. XIV, n $^{\circ}$ 3, dezembro - 2020 
de qualificação profissional em turismo não se revela tão expressiva em publicações. No site Publicações de Turismo, que indexa mais de 11 mil artigos da área do turismo e afins, apenas 12 artigos possuem 'qualificação profissional' nos títulos ou palavras-chave ${ }^{4}$. Nessa restrita produção, aborda-se desde a perspectiva de competitividade do setor até o debate de seus aspectos educacionais e trabalhistas (CATARAMBY; COSTA, 2004; TOMAZONI, 2007; MARANHÃO et. al., 2010; NOGUEIRA; COSTA NETO; SILVA, 2013), com raras publicações sobre políticas específicas do setor (PARENTE; MOESCH, 2016; MEIRA; KUSHANO; NEVES, 2018; SILVA, 2019).

Nesse sentido, investigar as metodologias de pesquisa utilizadas nas publicações sobre qualificação profissional pode contribuir tanto para o aprofundamento das pesquisas quanto para a ampliação de pesquisas voltadas ao setor do turismo. Por isso, levantam-se as seguintes questões: quais são as metodologias utilizadas para abordar o tema da qualificação profissional? E como tais metodologias podem contribuir para a investigação sobre qualificação em turismo?

Desta forma, o objetivo geral deste trabalho é analisar as metodologias utilizadas em pesquisas nos campos de estudo das políticas públicas de qualificação profissional e da qualificação profissional em turismo. Para tanto, incialmente foi realizado um levantamento das pesquisas nesses campos de estudo, identificando-se as metodologias nelas utilizadas. Posteriormente, foram analisadas as metodologias e suas possíveis contribuições para o objeto de estudo 'políticas públicas de qualificação profissional em turismo'.

A metodologia utilizada na presente pesquisa se baseou em uma revisão integrativa de literatura (CHUEKE; AMATUCCI, 2015) acerca dos campos de estudo indicados no objetivo geral, a partir de um levantamento bibliográfico nas bases de dados Scopus, Web of Science, Scielo, Spell, Redalyc e Google Acadêmico.

A qualificação profissional é um processo complexo5: é ao mesmo tempo um percurso educativo e um aspecto do trabalho na contemporaneidade; e, na medida em que educação e trabalho são elementos chave para a construção de cidadania, autonomia e desenvolvimento humano das pessoas, a qualificação configura também um instrumento político para os atores sociais envolvidos (MANFREDI, 1999; MOURÃO, 2009). Assim, com a análise de metodologias proposta neste estudo, buscam-se duas contribuições: 1) No âmbito científico-metodológico, apontar possíveis formas de abordagem ao objeto qualificação profissional; 2) No âmbito ético-político, propiciar a ampliação de investigações com rigor metodológico sobre políticas públicas de turismo, especificamente no eixo da qualificação profissional,

\footnotetext{
${ }^{4}$ Disponível em http://www.each.usp.br/turismo/publicacoesdeturismo/index.html. Acesso em 18 de maio de 2020 .

${ }^{5}$ Complexo, conforme defende Morin (2006), como um emaranhado de determinação que forma uma trama dialógica, recursiva e autoorganizada.
}

Observatório de Inovação do Turismo - Revista Acadêmica

Vol. XIV, n 3 , dezembro - 2020 
e, consequentemente, contribuir para desvelar discursos e práticas predominantes nessas ações do poder público.

\section{Referencial teórico}

Os principais conceitos identificados como norteadores das pesquisas sobre qualificação profissional estão relacionados a trabalho, educação profissional, qualificação profissional, políticas públicas, bem como a inter-relação dada entre eles.

O fenômeno da qualificação profissional na atualidade diz respeito a um processo que tem como objetivos trabalho e/ou emprego - seja na inserção de indivíduos desempregados ou no desenvolvimento de habilidades dos empregados. Isto torna fundamental o conceito de trabalho, pois a sua concepção tem grande influência nos objetivos de processos de qualificação. Silva (2014, p. 41) entende “[...]o trabalho enquanto uma relação estabelecida entre homem e natureza. Seu processo se torna possível à medida que o homem interage, se apropria e transforma o meio que está inserido".

Manfredi (2016, p. 21) aponta que as expressões concretas que o trabalho assume são históricas, "[...]variando de acordo com os modos de organização da produção e de distribuição de riqueza e poder". Com a reorganização da sociedade pelo sistema capitalista, o trabalho ganha novos significados, sendo convertido em elemento do processo de produção e acumulação do capital (NASCIMENTO, 2015). Neste cenário, ganham destaque o conceito de emprego e a discussão sobre empregabilidade. Nascimento (2015, p. 104) atenta para a diferenciação entre os conceitos de trabalho e emprego, postulando que "[...]enquanto trabalho é uma condição inerente ao homem, o emprego é uma situação socialmente determinada que implica ter condições e direitos assegurados".

Ao discutir a qualificação profissional como fator de empregabilidade, Araújo e Borges (2000, p. 14) defendem que "[...]a qualificação como elemento isolado é insuficiente para garantir o emprego na ausência de crescimento econômico". A disseminação de um discurso que atrela qualificação profissional a empregabilidade pode ser explicada por contribuições de Oliveira (2015). De acordo com o autor, políticas de qualificação são vistas pelo modelo capitalista neoliberal como uma resposta melhor do Estado ao desemprego do que reformas estruturais no sistema, visto que o desemprego estrutural favorece ao capital.

Dermeval Saviani (1994, p. 152) define trabalho como "[...]ato de agir sobre a natureza, adaptando-a às necessidades humanas". O autor coloca uma relação intrínseca entre trabalho, educação e existência humana, demonstrando que a educação para o trabalho constitui os seres humanos desde os primórdios. Ao recuperar a história dessa educação para o trabalho, Saviani revela como suas expressões 


\section{POLÍTICAS PÚBLICAS E QUALIFICAÇÃO \\ PROFISSIONAL: UMA ANÁLISE DAS \\ METODOLOGIAS DE PESQUISA}

foram adequadas aos modos de produção predominantes de cada época. Gradualmente, os seres humanos deixaram uma educação imediata ao momento de trabalho para estabelecerem uma bifurcação entre os momentos/espaços de educação (escola) e trabalho e, mais tarde no modo de produção capitalista, também uma bifurcação da educação entre formação geral e formação profissional (SAVIANI, 1994). Deitos e Lara (2016) corroboram a posição de que a educação profissional se ajusta às demandas de trabalho do sistema capitalista.

Manfredi (2016, p. 245) define educação profissional como “[...]programas, ações e práticas educativas (formais e não formais) cujo princípio e objetivo é a formação para o trabalho em todas as suas formas". Seguindo essa linha de pensamento, Barbosa e Porfírio (2009) apontam que sua configuração atual inclui escolas (públicas e privadas, de trabalhadores ou empresariais), universidades, Sistema S, ONGs e instituições de ensino profissional livre.

O Capítulo III da Lei de Diretrizes e Bases da Educação Nacional (LDBEN) trata da Educação Profissional e Tecnológica, subdividindo-a em três categorias: qualificação profissional ou FIC; ensino técnico de nível médio; e ensino superior de tecnologia (BRASIL, 1996). Entretanto, ainda que tratado nesta Lei, o conceito de qualificação profissional não possui uma definição única ou consensual.

Analisando a qualificação no século XIX, Oliveira (2013, p. 631) a define como “[...]conjunto de habilidades e conhecimentos adquiridos pelo trabalhador para exercer uma atividade de trabalho". Essa perspectiva corresponde a uma visão da qualificação como um fenômeno mais amplo do que a própria educação profissional institucionalizada nos moldes apontados por Manfredi (2016). Já Musse e Machado (2013, p. 237) defendem que a "[...]qualificação profissional, ou formação inicial e continuada, é direcionada para o mercado de trabalho e não eleva o nível de escolaridade do indivíduo". Essa outra perspectiva está alinhada com a categorização legal da qualificação.

As duas definições, porém, indicam as dimensões educativas e de trabalho dos processos de qualificação. Oliveira (2013 p. 632) acrescenta que “[...]a qualificação profissional é uma síntese de variáveis sociais, políticas e econômicas", incluindo o importante fator da dimensão política. A esse respeito, Mourão (2009, p. 142) acrescenta “[...] governo, os trabalhadores e as empresas" como atores sociais que possuem interesses diversos - e potencialmente conflitantes - na qualificação. Ferreti analisa os reflexos desses conflitos na produção teórico-conceitual e polariza as definições do conceito de qualificação profissional em concepções essencialistas e relativistas. Enquanto as primeiras se voltariam à adequação do trabalhador para as necessidades do mercado de trabalho, as segundas se recusariam a aceitar tal limitação dos processos educativos (FERRETI, 2004, p. 413).

Visto que a qualificação profissional possui também uma dimensão política, faz-se necessário compreender os conceitos de Estado, sociedade e políticas públicas. 
METODOLOGIAS DE PESQUISA

Nunes e Fernandes (2016, p. 65) acreditam que "[...]qualquer teoria da política pública precisa necessariamente explicar as inter-relações entre Estado, política, economia e sociedade". Pereira defende que Estado "[...]além de ser um conceito complexo, é um fenômeno histórico e relacional" (PEREIRA, 2009, p. 7, grifo da autora) - histórico por assumir diferentes expressões em cada época e relacional porque só pode ser compreendido a partir de uma relação intrínseca com a sociedade. Nunes e Fernandes, então, amarram a relação entre os três conceitos ao definir política pública como “[...]uma estratégia de ação pensada, planejada e avaliada a partir de uma racionalidade coletiva em que tanto o Estado como a sociedade desempenham papeis ativos" (NUNES; FERNANDES, 2016, p. 66).

Nesse sentido, o conceito de políticas públicas torna-se substancial para a área de qualificação profissional: o Estado precisa mediar a disputa política entre os atores sociais que possuem diferentes interesses na qualificação; ao passo em que também promove a qualificação como ação de desenvolvimento econômico.

Quanto às políticas públicas na área de qualificação, Ferreira reforça sua estreita relação com trabalho e emprego ao apontar que: "Um dos principais desdobramentos das políticas de emprego no Brasil nas últimas décadas foi a implantação de políticas de qualificação profisssional" (FERREIRA, 2013, p. 4). Em relação à posição do Estado quanto à política pública de emprego, Filgueiras acrescenta que esta "[...]acompanha as tendências recentes em outros âmbitos de política social no Brasil, com a descentralização para o nível municipal e a focalização nos segmentos considerados mais vulneráveis socialmente" (FILGUEIRAS, 2011, p. 450).

O destaque neste conjunto específico de conceitos na produção analisada pode ser explicado, em parte, pelo perfil das publicações, apresentado mais à frente. Em um movimento dialógico (MORIN, 2006), o campo científico dos periódicos e autores direcionam os olhares a seus respectivos recortes científicos, ao mesmo tempo em que a complexidade de aspectos e dimensões da qualificação profissional desperta interesse dos pesquisadores desses campos científicos. Antes de apresentar o perfil, porém, descreve-se a metodologia da presente pesquisa.

\section{Percurso metodológico}

Para fins desta pesquisa, entende-se o método da revisão integrativa de literatura como “[...]uma forma de pesquisa que procura analisar, criticar e sintetizar um corpo representativo de literatura sobre um tema em específico, integrando os achados por meio de frameworks e perspectivas" (TORRACO, 2005, apud CHUEKE; AMATUCCI, 2015, p. 2). Assim, utilizou-se como percurso metodológico os procedimentos sistematizados pelos autores Chueke e Amatucci $(2015$, p. 3) como “[...]passos principais 


\section{POLÍTICAS PÚBLICAS E QUALIFICAÇÃO \\ PROFISSIONAL: UMA ANÁLISE DAS \\ METODOLOGIAS DE PESQUISA}

da revisão integrativa de literatura". O Quadro 1 contém uma descrição, elaborada pelos autores, de cada um dos passos.

Quadro 1. Passos da revisão integrativa de literatura

\begin{tabular}{|l|l|}
\hline \multicolumn{1}{|c|}{ Passos } & \multicolumn{1}{c|}{ Descrição } \\
\hline $\begin{array}{l}\text { Passo 1 } \\
\text { Elaborar o protocolo de } \\
\text { pesquisa }\end{array}$ & $\begin{array}{l}\text { Elaborar o protocolo de pesquisa estabelecendo as perguntas que deverão } \\
\text { ser respondidas a partir da leitura sistemática de artigos. Estabelecer os } \\
\text { outputs ou displays que serão apresentados no artigo. }\end{array}$ \\
\hline $\begin{array}{l}\text { Passo 2 } \\
\text { Identificar os estudos mais } \\
\text { relevantes no campo }\end{array}$ & $\begin{array}{l}\text { Inicialmente, sugere-se realizar uma busca ampla em diferentes bases e } \\
\text { periódicos para identificar artigos de interesse. Para tanto, deverão ser } \\
\text { criados os critérios de inclusão e exclusão de artigos. Esses critérios de } \\
\text { busca devem estar alinhados à pergunta de pesquisa e a discussão em curso } \\
\text { no campo de conhecimento. }\end{array}$ \\
\hline $\begin{array}{l}\text { Passo 3 } \\
\text { Avaliar a qualidade dos estudos } \\
\text { levantados }\end{array}$ & $\begin{array}{l}\text { Criar uma ficha de avaliação de artigos com os critérios que vão caracterizar } \\
\text { se o artigo vai ou não constituir o corpo de artigos que serão analisados de } \\
\text { forma exaustiva. }\end{array}$ \\
\hline $\begin{array}{l}\text { Passo 4 } \\
\text { Sintetizar os dados coletados }\end{array}$ & $\begin{array}{l}\text { Consiste na fase de tabulação dos resultados, qualificando e explorando as } \\
\text { contradições e afinidades entre estudos. }\end{array}$ \\
\hline $\begin{array}{l}\text { Passo 5 } \\
\text { Integrar os resultados obtidos }\end{array}$ & $\begin{array}{l}\text { Gerar análises comparando e contrastando os dados. Deve-se buscar } \\
\text { responder à pergunta de pesquisa e apontar novos rumos para pesquisas } \\
\text { futuras. }\end{array}$ \\
\hline
\end{tabular}

Fonte: Chueke e Amatucci (2015)

Para identificar os estudos relevantes nos campos pesquisados, foi realizado um levantamento bibliográfico em seis bases de dados relevantes para o campo de estudos do turismo: Scopus e Web of Science, em razão do alcance internacional; Scielo, Spell e Redalyc, por abranger a produção dos países ibero-americanos; e Google Acadêmico, pela amplitude da base. Quanto ao recorte temporal, não houve limitante inicial prévio aos parâmetros de seleção, mas foi estabelecido um limitante final no ano de 2017. Esta limitação se deve à publicação, no ano seguinte, do PNT 2018-2022 (MTur, 2018), que estabeleceu a PNQT. Essa política aparece como um arranjo inédito de políticas públicas de qualificação profissional e de turismo, “[...]pois pressupõe uma articulação mais equilibrada entre as áreas" (SILVA, 2019 , p. 15). Com isso, entende-se que as pesquisas que se debruçam sobre esse arranjo tratam de uma realidade em processo, com resultados ainda não estabelecidos, e, portanto, foram excluídas da presente pesquisa.

Foram realizadas três buscas nas bases, utilizando diferentes conjuntos de palavras-chave. A primeira, visando um levantamento mais amplo, incluiu as palavras-chave "qualificação", "qualificação profissional", "política de qualificação", "professional qualification", "qualification policy" e “calificación profesional". Nos resultados com até 150 artigos, foi realizada seleção para análise; para resultados com mais de 150 artigos, a busca foi refinada por meio de palavras-chave mais específicas.

A segunda busca utilizou-se de combinações das palavras-chave: "qualificação profissional" com "política" ou "turismo"; "professional qualification" com "politics" ou "tourism"; e "calificación

Observatório de Inovação do Turismo - Revista Acadêmica

Vol. XIV, $\mathrm{n}^{\circ} 3$, dezembro - 2020 


\section{POLÍTICAS PÚBLICAS E QUALIFICAÇÃO \\ PROFISSIONAL: UMA ANÁLISE DAS \\ METODOLOGIAS DE PESQUISA}

profesional" com "política". A mesma quantidade da primeira busca foi utilizada como parâmetro para seleção ou refinamento dos resultados.

Enfim, a terceira busca se baseou no uso de uma palavra-chave mais específica - "políticas de qualificação profissional" - para as bases em que todos as buscas resultavam mais de 150 artigos. No caso da base Redalyc, a terceira busca permitiu a seleção dos artigos. No caso da base Google Acadêmico, os resultados ainda eram volumosos, então foi utilizado como parâmetro a seleção nos 30 primeiros trabalhos listados, em razão da base alcançar muitos trabalhos que não estão indexados nas bases anteriores.

As três buscas resultaram em 630 trabalhos recuperados nas seis bases.

Os critérios de seleção dos artigos para análise final se basearam na seleção ou exclusão de artigos tendo como base parâmetros temáticos previamente estabelecidos. A lista dos parâmetros consta no Quadro 2.

Quadro 2. Parâmetros temáticos para seleção ou exclusão dos artigos

\begin{tabular}{|c|c|}
\hline Parâ & dos artigos \\
\hline 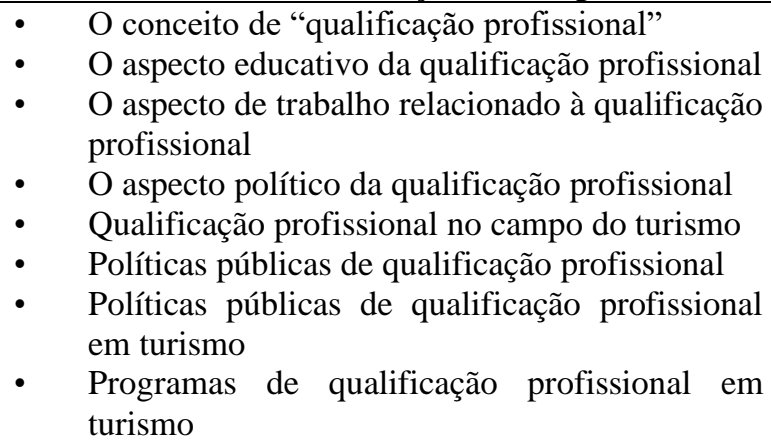 & $\begin{array}{l}\text { - Trabalhos de qualificação profissional em outras } \\
\text { áreas, tais como educação física; saúde; serviço } \\
\text { social; contabilidade; matemática; administração } \\
\text { - } \begin{array}{l}\text { Qualificação de profissionais da educação } \\
\text { Políticas e programas de qualificação profissional } \\
\text { de outros países }\end{array} \\
\text { Qualificação profissional no contexto da } \\
\text { educação superior } \\
\text { Trabalhos onde os autores usam "qualificação } \\
\text { profissional" como sinônimo indistinto de } \\
\text { "educação profissional" }\end{array}$ \\
\hline
\end{tabular}

Fonte: Elaborado pelo autor.

Assim, foram sistematizadas três etapas de identificação dos parâmetros nos trabalhos: primeira, nos títulos; segunda, nos resumos; terceira, nas sessões dos artigos (caso os títulos e resumos não deixassem clara a relevância do artigo para a presente pesquisa).

Com base nos parâmetros, 49 trabalhos foram selecionados para análise. Em seguida, foi realizada avaliação da qualidade dos trabalhos selecionados. O único critério utilizado para exclusão de artigos neste passo foi a impossibilidade de identificação de alguma metodologia, mesmo por inferência ${ }^{6}$. Como resultado, quatro não contribuíam para alcançar os objetivos deste estudo, permanecendo 45 para análise final e síntese integradora.

${ }^{6}$ Como será apresentado na seção 5, em alguns artigos foi possível inferir-se que a metodologia utilizada foi a pesquisa bibliográfica.

Observatório de Inovação do Turismo - Revista Acadêmica

Vol. XIV, $\mathrm{n}^{\circ} 3$, dezembro - 2020 


\section{POLÍTICAS PÚBLICAS E QUALIFICAÇÃO \\ PROFISSIONAL: UMA ANÁLISE DAS \\ METODOLOGIAS DE PESQUISA}

A partir dessa integração, será apresentado o perfil das publicações - veículos de publicação e formação dos autores.

\section{Perfil das publicações no campo das políticas públicas de qualificação profisssional}

Em relação à produção de dados, dos 45 trabalhos analisados, 24 apresentaram dados empíricos, enquanto 21 focaram-se em pesquisas teóricas. Conforme o Gráfico 1 , as revistas/periódicos/instituições, onde as pesquisas são publicadas, concentram-se nas áreas de educação e administração, com algum destaque em economia e turismo.

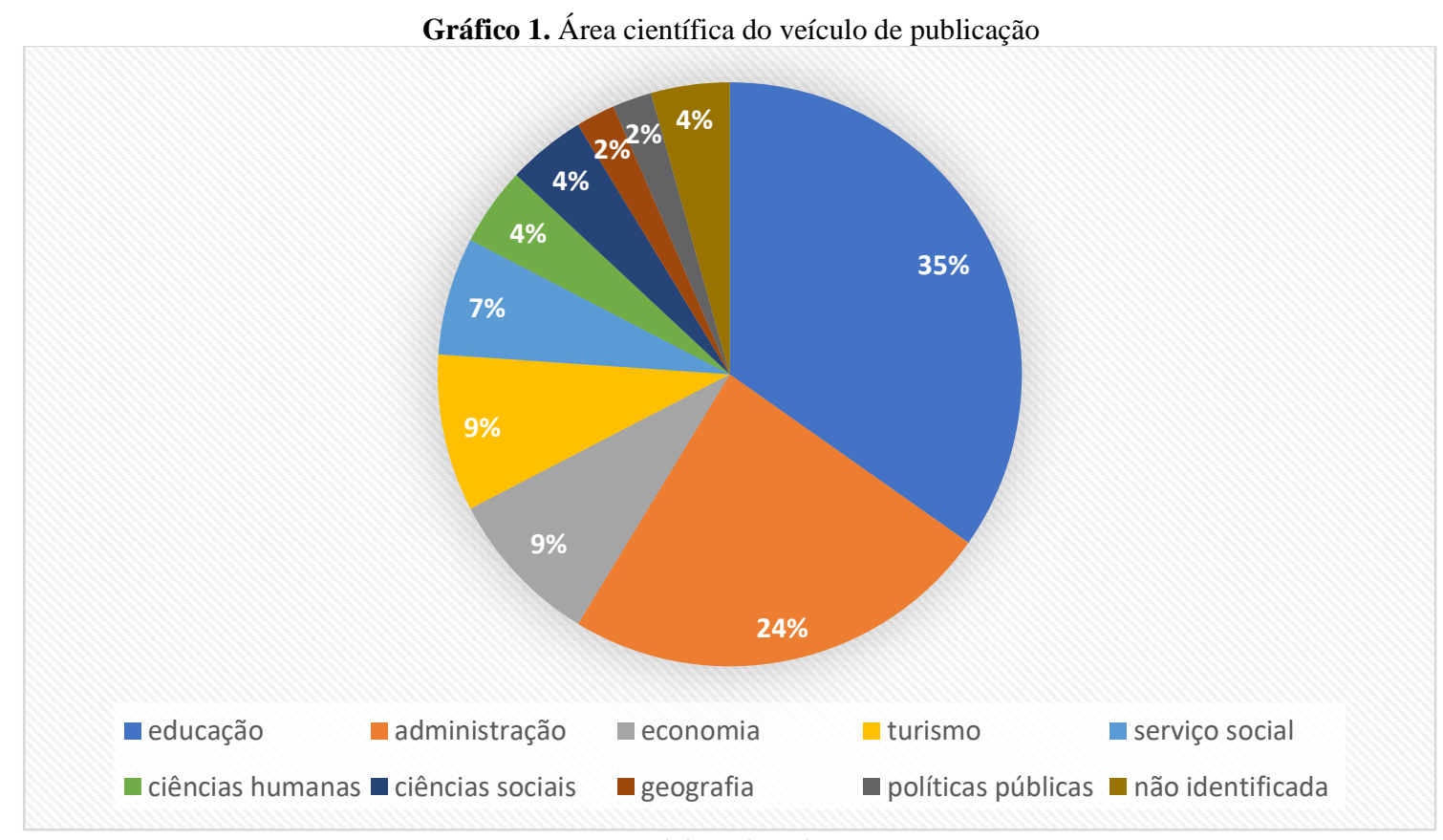

Fonte: Elaborado pelo autor.

O destaque destas áreas pode ser rastreado na formação dos autores das pesquisas. Como pode ser observado no Gráfico 2, educação, administração e economia são as áreas de onde advêm a maior parte dos autores do tema. Também se mostram relevantes as áreas de turismo, sociologia e ciências políticas.

O tema das políticas de qualificação profissional é um objeto de estudo interdisciplinar, o que permite autores de diferentes áreas abordá-lo. Todavia, é coerente que os autores utilizem o enfoque de suas áreas de formação e, portanto, procurem publicar suas pesquisas nas mesmas. Esta pode ser, então, uma das causas da semelhança entre os panoramas de formação dos autores e áreas dos veículos de publicação.

Observatório de Inovação do Turismo - Revista Acadêmica

Vol. XIV, n 3 , dezembro - 2020 


\section{Gráfico 2. Área de formação dos autores}

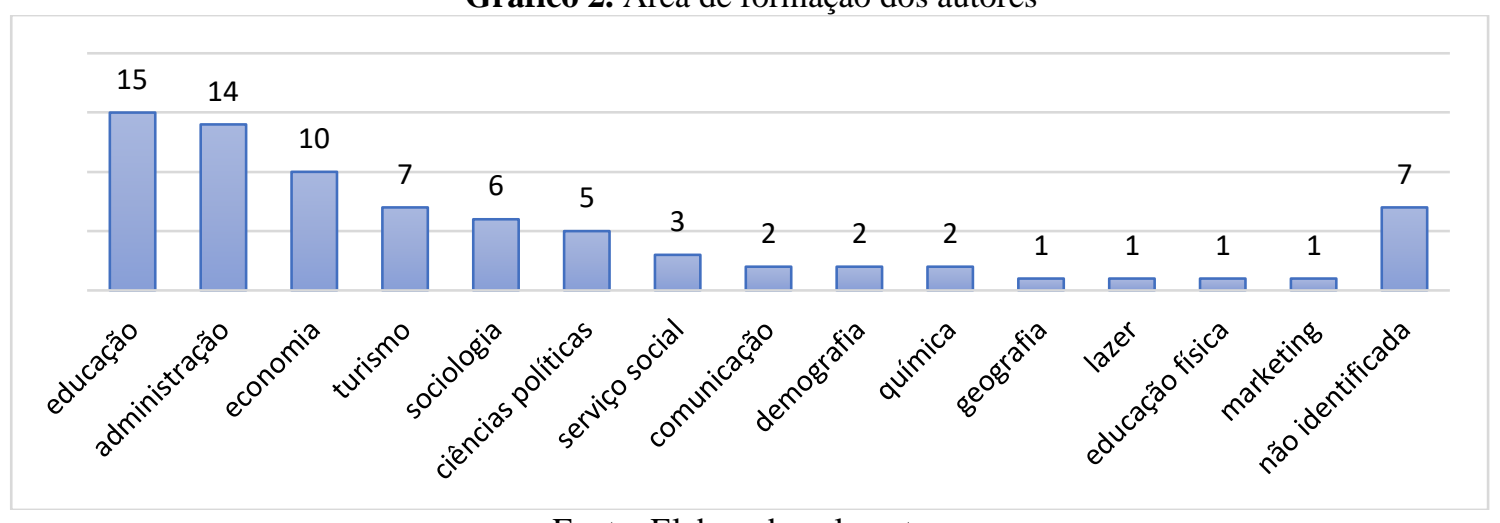

Fonte: Elaborado pelo autor.

\subsection{Evolução da produção acadêmica e dos objetos de estudo}

Conforme mencionado, o levantamento dessa pesquisa não datou um recorte temporal inicial, mas apenas um recorte final em 2017. Com isso, foram encontrando resultados a partir de 1989. Conforme o Gráfico 3, é perceptível uma escassez na produção antes dos anos 2000 e sua intensificação a partir de 2013. Uma possível razão para este aumento, é a instituição de novas políticas nacionais de qualificação.

Gráfico 3. Evolução da produção das pesquisas levantadas

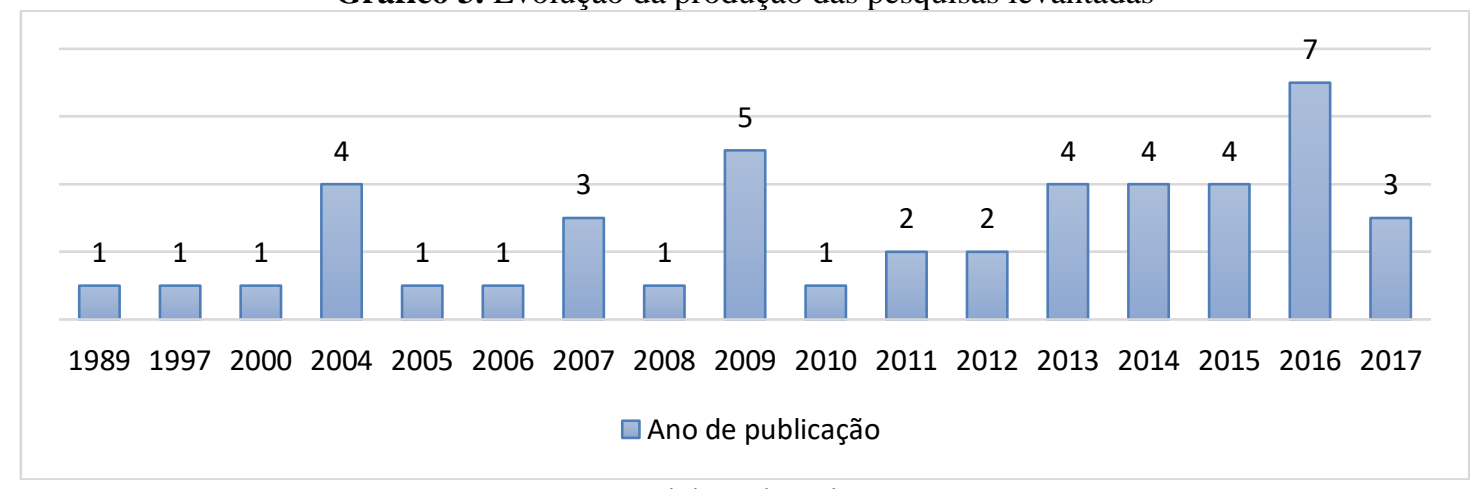

Fonte: Elaborado pelo autor.

Traçando uma linha temporal das pesquisas levantadas neste estudo, os temas de estudo limitavam-se inicialmente ao debate conceitual sobre qualificação profissional e sua relação com a empregabilidade (CRIVELLARI; MELO, 1989; GARAY, 1997; ARAÚJO; BORGES, 2000; FERRETI, 2004). Já nos anos 2000, despontavam as pesquisas acerca das políticas públicas do setor. Além de traçar um histórico das políticas de qualificação, os autores também traçam seus fundamentos nas políticas de trabalho e educação profissional (TREVISAN; VELOSO, 2007; SERRA, 2009; PRESTES; VERAS, 2009). É necessário notar que, no começo da década, estava em vigor como política

Observatório de Inovação do Turismo - Revista Acadêmica 103

Vol. XIV, n $^{\circ}$, dezembro - 2020 
de qualificação o Plano Nacional de Qualificação do Trabalhador (Planfor), e, após seu término, pesquisas passaram a analisar seu desempenho (BULHÕES, 2004; OLIVEIRA; RIOS-NETO, 2007).

Em 2003, o Planfor é substituído pelo Plano Nacional de Qualificação (PNQ) e, então, as pesquisas abordam não apenas o novo plano, mas sua execução no nível local - por meio de programas e comissões municipais (FARIA; MONTEIRO, 2004; BARBOSA; PORFÍFIO, 2009). Embora pesquisas focadas apenas em debater o conceito de qualificação tenham menor frequência ao passar das décadas, surge um novo debate conceitual acerca da diferença entre os conceitos de qualificação e competência (VIEIRA; LUZ, 2005; AMARO, 2008; ASSUNÇÃO, 2016).

A partir de 2010, o aumento da produção de pesquisas na área permite continuar as discussões já estabelecidas com a abordagem de novas questões. Novos olhares são lançados para a trajetória histórica das políticas de qualificação, ampliando o alcance temporal com programas anteriores ao Planfor e ao século XX (OLIVEIRA, 2013; ARAÚJO; LIMA, 2014; MONTALVÃO, 2015). Permanecem também estudos sobre o PNQ (ROCHA-VIDIGAL; VIDIGAL, 2012; MELO, 2013) e a relação da qualificação com condições de trabalho e empregabilidade no Brasil (OLIVEIRA, 2015; NUNES; FERNANDES, 2016; ARAÚJO; ANTIGO, 2016).

Em 2011, é instituído o Programa (Pronatec), configurando-se como principal ação do poder público na qualificação profissional. Diversos trabalhos abordam o programa, avaliando a qualidade da educação profissional que promove, sua concepção político-ideológica e seus resultados (CASSIOLATO; GARCIA, 2014; NASCIMENTO, 2015; DEITOS; LARA; ZANARDINI, 2015). Também destaca-se a produção de pesquisas sobre as políticas de nível estadual e municipal - a política do Complexo Petroquímico do Rio de Janeiro (FERREIRA, 2013) e o Plano Setorial de Qualificação (PETERINNI, 2016), bem como sobre programas sociais que integram a qualificação ao seu escopo como Seguro-desemprego (BALESTRO; MARINHO; WALTER 2011), Programa Nacional de Inclusão de Jovens (FRIEDERICH; BENITE; BENITE, 2014) e Programa Mulheres Mil (CORCETTI; LORETO, 2017).

Quanto as pesquisas sobre qualificação no campo do turismo, os objetos de estudo são relacionados à sua influência na economia - competitividade e gestão de destinos e empresas - e ao trabalho em turismo - formação e empregabilidade (CATRAMBY; COSTA, 2004; TOMAZONI, 2007; SILVA, 2014; CONCEIÇÃO; FRAGA; CONCEIÇÃO, 2016; PIMENTEL; PAULA; OLIVEIRA, 2016).

Como pontos fortes das pesquisas, podem-se elencar dois fatores. Primeiro, uma notável investigação do histórico das políticas de qualificação, embasadas inclusive nas políticas de emprego e educação profissional. Segundo, a abordagem a programas advindos de diferentes regiões, instituições 


\section{POLÍTICAS PÚBLICAS E QUALIFICAÇÃO \\ PROFISSIONAL: UMA ANÁLISE DAS \\ METODOLOGIAS DE PESQUISA}

educativas, delineando um panorama mais completo que apenas o histórico de políticas federais. Em contrapartida, poucos trabalhos se debruçam para a avaliação dos programas em termos de impactos e resultados, ao passo que grande parte deles se prende à discussão da evolução histórica do conceito. No campo do turismo, também é significativa a insuficiência de pesquisas sobre os programas de qualificação do setor e avaliação dos mesmos.

Analisado o perfil e histórico das publicações, pode-se então analisar as metodologias utilizadas nesse conjunto de trabalhos.

\section{Qualificação profissional e suas metodologias de pesquisa}

Foram identificados 20 procedimentos metodológicos ${ }^{7}$ de pesquisa nos trabalhos analisados, indicados no Gráfico 4. O resultado total supera o número de 45 trabalhos devido a muitos deles se utilizarem de mais de um procedimento por pesquisa ${ }^{8}$.

Gráfico 4. Procedimentos metodológicos utilizados nas pesquisas

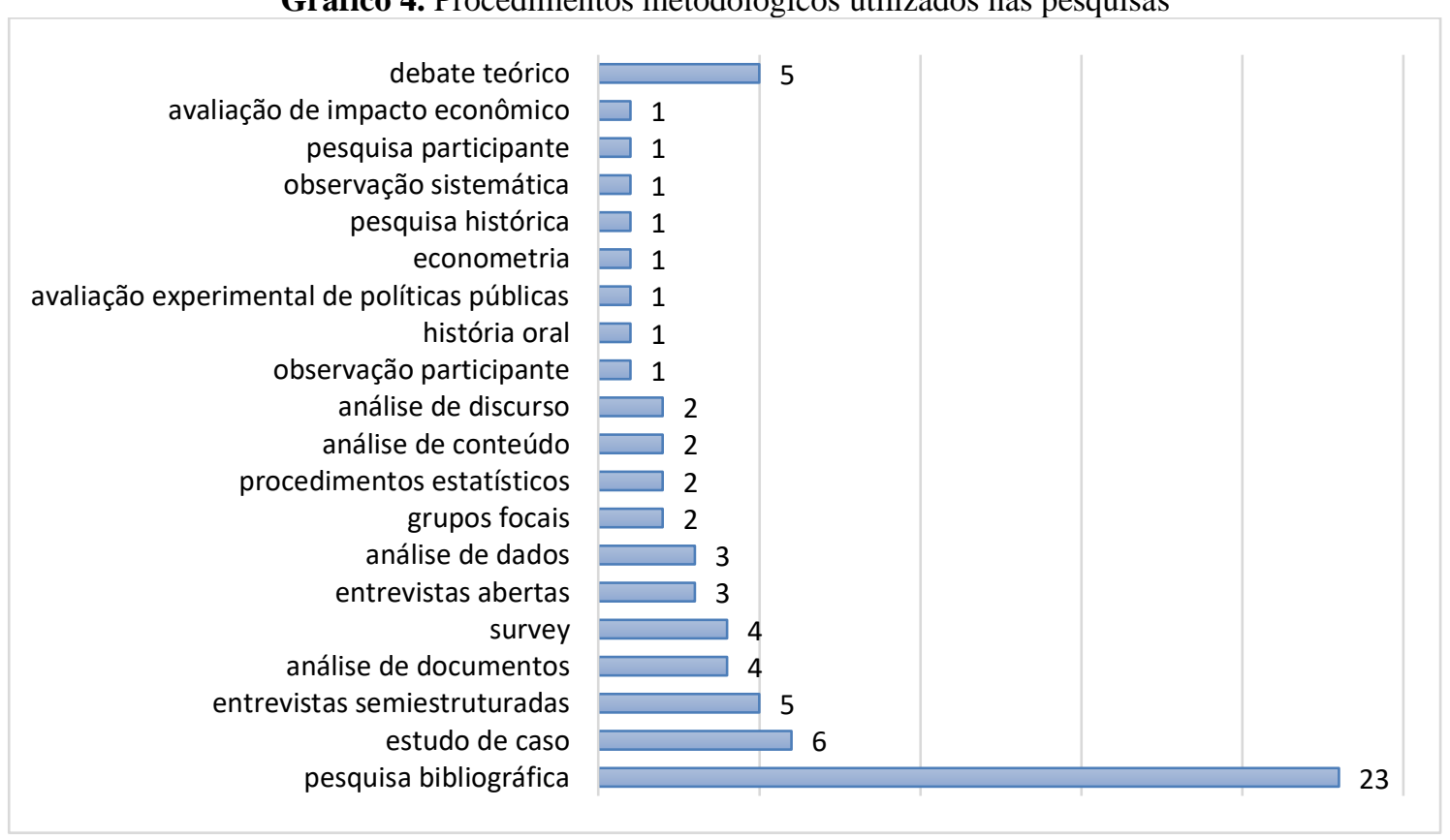

Fonte: elaborado pelo autor.

\footnotetext{
${ }^{7}$ Utilizou-se a terminologia 'procedimentos metodológicos' por dois motivos. Primeiro, a terminologia utilizada pelos autores dos artigos analisados é heterogênea, variando entre 'método', 'metodologia' ou 'instrumentos metodológicos', muitas vezes ao referir-se ao mesmo procedimento. Nesse sentido, seria arbitrário categorizar determinados procedimentos como método ou não, pois alteraria o posicionamento teórico dos autores. Segundo, também não seria adequado denominar os procedimentos na presente análise como 'metodologias', pois carregaria o sentido de totalidade dos procedimentos utilizados. Porém, em muitos dos artigos, foram utilizados mais de um procedimento, não sendo possível separar quando os autores utilizaram cada procedimento como uma totalidade ou como uma parte da metodologia.

${ }^{8}$ Destaca-se que o número contabilizado para o procedimento da pesquisa bibliográfica inclui: trabalhos que explicitam o seu uso; e trabalhos que não explicitam o uso de nenhum procedimento, mas é possível inferir o uso da pesquisa bibliográfica pela estrutura do artigo, voltada a levantamentos bibliográficos e/ou discussões teórico-conceituais. Considerou-se válido também registrar uma categoria "debate teórico" para os trabalhos que se utilizaram apenas de pesquisas bibliográficas, mas que não apresentavam problemáticas e resultados.
}

Observatório de Inovação do Turismo - Revista Acadêmica

Vol. XIV, n $^{\circ}$ 3, dezembro - 2020 


\section{POLÍTICAS PÚBLICAS E QUALIFICAÇÃO \\ PROFISSIONAL: UMA ANÁLISE DAS \\ METODOLOGIAS DE PESQUISA}

Em consonância com a trajetória dos objetos de estudo, até os anos 2000, as pesquisas na área utilizavam apenas pesquisas bibliográficas. No período 2001-2005 aparecem os primeiros estudos de caso (único e múltiplo), utilizando-se de análise documental e entrevistas abertas. Entre 2006 e 2010 passam a ser utilizadas entrevistas semiestruturadas, grupos de foco e surveys. O estudo de caso do período incorpora também o procedimento de análise de conteúdo. Embora até esta época, as pesquisas sobre qualificação em turismo tivessem sido apenas bibliográficas, em 2007, Oliveira e Rios-Neto surgem com uma metodologia para avaliação das políticas públicas de qualificação.

De 2011 a 2015, quatro novos procedimentos foram utilizados nas pesquisas da área: econometria; pesquisa histórica; entrevista de história oral; e pesquisa participante. Neste período, percebe-se um maior uso de combinações dos procedimentos de entrevista, análise documental e pesquisa bibliográfica (inclusive com os novos procedimentos introduzidos). A partir de 2016, destacaram-se o uso de procedimentos estatísticos mais específicos, a avaliação de impactos econômicos e o uso de análise de discurso em estudo de caso. As pesquisas em turismo, a partir de 2010, também se diversificaram com uso de estudo de caso, entrevistas e procedimentos estatísticos. A seguir, será apresentado como os procedimentos metodológicos identificados contribuem para as pesquisas da área.

\subsection{Pesquisa bibliográfica}

A pesquisa bibliográfica é o procedimento mais utilizado pelos trabalhos levantados e, de uma forma geral, apresentou discussões mais generalistas quando utilizada como único procedimento metodológico da pesquisa. Isto é, as pesquisas que a utilizaram objetivavam debates mais amplos e conceituais em detrimento de resultados específicos e práticos. Um dos objetivos mais recorrentes nas pesquisas bibliográficas era o debate sobre o conceito de qualificação profissional. Os resultados apontaram para uma diversidade de concepções, de economicistas a voltadas para cidadania, demarcando que o fenômeno possui dimensões social, econômica, política, educacional e psicológica (CRIVELARI; MELO, 1989; GARAY, 1997; FERRETI, 2004; ASSUNÇÃO, 2016; DEITOS; LARA, 2016).

Também é recorrente como objetivo destas pesquisas o levantamento da evolução histórica das políticas de qualificação profissional, visando analisar tanto os modelos de educação estabelecidos por elas quanto o beneficiamento de grupos específicos, como jovens, trabalhadores e atores locais (FILGUEIRAS, 2011; ARAÚJO; LIMA, 2014; MONTALVÃO, 2015).

Outros temas que figuram como foco destas pesquisas são: discutir a relação entre qualificação e as políticas de trabalho e emprego (MIRANDA; ARAÚJO, 2006; TOMAZONI, 2007; NUNES; 
PROFISSIONAL: UMA ANÁLISE DAS

METODOLOGIAS DE PESQUISA

FERNANDES, 2016); e debater a construção de métodos de avaliação de políticas sociais (PRESTES, 2012).

\subsection{Análise de dados, análise documental e pesquisa histórica}

Dentro do universo de pesquisas levantadas, o procedimento de análise de dados foi utilizado de uma mesma forma. Foram selecionados dados socioeconômicos para traçar o perfil de determinados grupos (alunos, trabalhadores) ou da população e, em seguida, os dados foram confrontados com as perspectivas teóricas que os autores embasaram com pesquisas bibliográficas (MELO, 2013; CASSIOLATO; GARCIA, 2014; OLIVEIRA, 2015). Por fim, o objetivo do uso deste procedimento era avaliar a influência de determinados programas de qualificação na realidade dos grupos pesquisados.

Já a análise documental, foi utilizada para diversos fins, dentre eles: avaliar bases políticoideológicas de programas de qualificação por meio da análise de seu projeto escrito (CORCETTI; LORETO, 2017); investigar o funcionamento de instituições públicas por meio de atas de reuniões (BARBOSA; PORFÍRIO, 2009); e complementar a base de informações de entrevistas com documentos fornecidos pelos próprios entrevistados (FARIA; MONTEIRO, 2004). Por fim, a análise documental foi meio para realização de pesquisa histórica. Para investigação das bases históricas de ações de qualificação, Oliveira (2013) realizou análise de documentos do século XIX, como jornais, registros e publicações de associações da época, e documentos governamentais de cunho econômico.

\subsection{Procedimentos estatísticos e econômicos}

Os procedimentos metodológicos com enfoque econômico - avaliação de impactos econômicos e análise com modelos econométricos - tinham como objetivos: analisar a relação entre qualificação e empregabilidade dos alunos; e traçar o perfil destes alunos, analisando a influência de variáveis como sexo, etnia, idade, escolaridade e situação de emprego (MUSSE; MACHADO, 2013; PETTERINI, 2016). Os procedimentos estatísticos identificados - técnica de amostragem particionada e estudo univariado de matrizes de transição - tiveram função de ferramenta para trabalhar os dados obtidos com os modelos econômicos (PIMENTEL; PAULA, 2016; ARAÚJO; ANTIGO, 2016).

Destaca-se o uso de survey. Notadamente, este procedimento metodológico diferenciou-se das demais formas de entrevistas ou questionários pelo maior número de respondentes. Os resultados alcançados nas pesquisas a partir deste procedimento têm cunho quantitativo, sendo apresentado por meio de análises estatísticas dos dados. Os objetivos do uso de survey centraram-se em apreender a 
opinião de classes de indivíduos (empresários do trade turístico, formandos, beneficiários de programas de qualificação) e quantificar a oferta de qualificação profissional das instituições responsáveis (MOURÃO, 2009; LEMOS; DUBEUX; PINTO, 2009; BALESTRO; MARINHO; WALTER, 2011).

\subsection{Entrevistas}

Foram utilizadas nas pesquisas entrevistas abertas, semiestruturadas, grupos de foco e história oral. Os grupos de foco visaram investigações semelhantes às surveys, eventualmente utilizados conjuntamente, e buscaram a perspectiva de alunos sobre os programas de qualificação pelos quais foram contemplados (TREVISAN; VELOSO, 2007; BALESTRO; MARINHO; WALTER, 2011). Quanto às entrevistas abertas, o objetivo do seu uso foi apreender o processo de formulação e implementação das políticas de qualificação por meio da abordagem aos gestores dos órgãos públicos e das instituições de ensino (FARIA; MONTEIRO, 2004; FERREIRA, 2013). As entrevistas semiestruturadas apresentaram objetivos muitos semelhantes, acrescendo-se abordagem a empreendimentos turísticos (PIMENTEL; PAULA; OLIVEIRA, 2016; CONCEIÇÃO; FRAGA; CONCEIÇÃO, 2016; UNGHERU; ISAYAMA, 2017).

As diferentes formas de entrevista buscavam a perspectiva dos atores envolvidos, mas enquanto as entrevistas abertas e semiestruturadas enfocaram o processo de construção das políticas, as surveys e os grupos de foco abordaram os seus resultados.

De forma similar ao objetivo das entrevistas abertas, porém com muito mais profundidade na experiência individual, Silva utiliza o procedimento metodológico da história oral com "[...] ]objetivo de perceber de forma mais pormenorizada como os cursos de qualificação são atrelados as vivências desses trabalhadores no mercado turístico em que estão inseridos" (SILVA, 2014, p 20). Nesse sentido, podese apreender que enquanto as entrevistas abertas analisavam a política de qualificação sob a perspectiva dos indivíduos, a história oral analisa a realidade dos indivíduos a partir da influência da política.

\subsection{Estudos de caso, análise de conteúdo e análise de discurso}

O procedimento metodológico de estudo de caso foi utilizada nas pesquisas levantadas por três motivos principais. Primeiro, com objetivo de analisar como a incorporação da ideia de competência em substituição à de qualificação influencia no funcionamento de empresas ou indústrias (AMARO, 2008). Segundo, para estudar o funcionamento de instituições, como órgãos de implementação de políticas (FARIA; MONTEIRO, 2004) ou empreendimentos turísticos (PIMENTEL; PAULA; OLIVEIRA, 
2016). Por fim, também visaram analisar ações públicas de qualificação, em suas dimensões ideológica ou de implementação (CORCETTI; LORETO, 2017; SENRA et al, 2017).

Destaca-se que os estudos de caso utilizam diversos outros procedimentos metodológicos para alcance de seus objetivos. Dentre os aqui citados, foram utilizados de forma complementar: pesquisa bibliográfica; surveys e procedimentos estatísticos; entrevistas abertas e semiestruturadas; análises de documentos, de conteúdo e de discurso.

Em relação a análise de conteúdo, o procedimento foi utilizado em entrevistas abertas - a fim de categorizar perfis socioeconômicos preferências profissionais (TREVISAN; VELOSO, 2007) - e em documentos de empresas - para apreender a concepção do conceito de qualificação profissional estabelecido (AMARO, 2008). Já a análise de discurso centrou-se em investigar as ideologias de atores sociais em espaços de participação popular (FARIA; MONTEIRO, 2004), bem como de formuladores de políticas de qualificação (CORCETTI; LORETO, 2016).

\subsection{Pesquisa participante e avaliação experimental de políticas}

Embora estes dois procedimentos tenham sido utilizados apenas uma vez nas pesquisas analisadas, suas funcionalidades merecem destaque. A avaliação experimental de políticas públicas é utilizada por Oliveira e Rios-Neto com objetivo medir a eficiência do Planfor na inserção dos beneficiados no mercado de trabalho. Os autores apresentam um extenso debate para delimitar o método de avaliação considerado mais adequado para uma política de qualificação profissional. Apresentam a metodologia "antes/depois", que compara o desempenho em empregabilidade de um mesmo grupo antes e depois da política; mas defendem a superioridade da metodologia "experimental", na qual os beneficiários da política são comparados a um grupo de controle não beneficiário (OLIVEIRA; RIOSNETO, 2007).

À medida que uma ação de qualificação tem como objetivo promover a empregabilidade dos indivíduos beneficiados, uma avaliação mais completa necessita investigar a situação de emprego destes indivíduos após a formação. Assim, este método torna-se individualmente relevante para a presente pesquisa por configurar uma forma de avaliação prática dos resultados de uma política implementada.

Outro procedimento metodológico de destaque foi a pesquisa participante, desta vez não por avaliar políticas, mas instaurar uma forma de intervenção na mesma. Para os autores Friederich, Benite e Benite (2014), a pesquisa participante é uma forma alternativa de produção do conhecimento que visa incorporar sujeitos sociais usualmente marginalizados deste processo. Os autores consideram três etapas para realização deste procedimento. 
A primeira - investigação social - consistiu no “[...]desenvolvimento de uma estratégia de participação deste grupo (os egressos do Projovem - Goiânia) situado histórica e socialmente no presente processo de produção coletiva de conhecimento em torno de suas vivências e interesses" (FRIEDERICH; BENITE; BENITE, 2014, p. 194). Na segunda - trabalho educacional - os beneficiados do programa "[...]foram convidados a participar desta pesquisa visando a contribuir para uma possível reprogramação das atividades educativas do programa de acordo com suas necessidades e interesses" (FRIEDERICH; BENITE; BENITE, 2014, p. 194). Por fim, com a etapa da ação, os pesquisadores pretenderam "[...]propor que, uma vez conhecida a antítese presente na proposta de formação do Projovem, se possa indicar caminhos para redimensionamento da proposta" (FRIEDERICH; BENITE; BENITE, 2014, p. 195).

A partir destas três partes da metodologia de pesquisa participante, os autores defendem que seja possível uma modificação na realidade dos indivíduos pelo incentivo da política pública ao pensamento crítico.

Apresentados individualmente os procedimentos metodológicos utilizados nas pesquisas analisadas, a seguir é realizada uma síntese e discussão dos dados, confrontando os propósitos inferidos do uso dos procedimentos com a contribuição para a pesquisa sobre o processo de qualificação profissional em turismo.

\section{Contribuição das metodologias à pesquisa em qualificação profissional em turismo}

Pesquisas de cunho bibliométrico sobre a produção científica no turismo têm apontado um crescimento no volume de artigos publicados, mas não necessariamente acompanhado de garantia de qualidade das pesquisas (SANTOS; REJOWSKY, 2012) ou de estudos particularmente focados na análise de metodologias (PICAZO-PERAL; MORENO-GIL; LEÓN-GONZÁLEZ, 2012). A evolução quantitativa das pesquisas analisadas e seus tratamentos dispensados ao âmbito metodológico apontam uma coincidência parcial com tal realidade. Ainda assim, pode-se inferir diversas contribuições das pesquisas analisadas para a pesquisa sobre qualificação em turismo - especialmente considerando-se a escassa produção sobre o tema.

O tema "Políticas públicas de qualificação profissional em turismo" possui diversas variáveis, o que possibilita o uso de todos os procedimentos metodológicos analisados. A pesquisa bibliográfica tem grande valor para estabelecer as bases de pesquisas nessa área. Primeiro, como o conceito de qualificação não possui uma única definição, é importante que a pesquisa estabeleça qual concepção está utilizando. Segundo, analisar a situação de uma política pública - seja nacional ou local - requer 
alguma compreensão da conjuntura que levou a sua implementação (panorama econômico, político, social, etc). Estes debates conceituais e delimitações da evolução histórica são, justamente, os possíveis usos da pesquisa bibliográfica identificados no levantamento.

Entretanto, alguns procedimentos estão mais atrelados a certas variáveis e propensos a serem utilizados em conjunto a outros. Análises voltadas à dimensão econômica e de trabalho da qualificação, podem se focar mais no uso de métodos quantitativos. Para traçar o perfil socioeconômico dos beneficiados e verificar a influência dos programas de qualificação em sua renda e empregabilidade, é possível utilizar análise de dados (quando estes estiverem previamente disponíveis) ou levantar tais informações por meio de surveys. Podem ser utilizados também procedimentos estatísticos como ferramenta para trabalhar os dados e os procedimentos econômicos para as análises.

Caso o objetivo da pesquisa enfoque a dimensão educativa, é fundamental o uso da análise documental nos projetos político-pedagógicos dos programas e cursos. Nesse sentido, pode ser utilizada conjuntamente análise de conteúdo nos referidos documentos. Como não necessariamente a concepção educativa idealizada é plenamente convertida nas práticas pedagógicas, também contribuem procedimentos de entrevista - abertas, semiestruturada ou grupos focais - que abordem os atores sociais envolvidos no processo, como alunos e professores.

Estes mesmos procedimentos podem ser utilizados para abordar a dimensão política da qualificação profissional. Análises documentais e de conteúdo sobre os projetos das ações de qualificação podem apreender o posicionamento político-ideológico declarado na política, enquanto as entrevistas verificam a coerência entre este posicionamento oficial e o efetivado na prática. Destaca-se também para as pesquisas com este foco, a análise de discurso que - utilizada tanto em documentos quanto em entrevistas - permite buscar o posicionamento não declarado pelos atores sociais.

Em relação aos objetivos de pesquisa, os procedimentos também indicam caminhos diferentes. Entrevistas e surveys permitem apreender a percepção dos atores envolvidos no fenômeno da qualificação profissional; já análise de dados e documentais, investigar as informações disponíveis sobre os programas. No âmbito da análise de ações práticas, os procedimentos econômicos e a avaliação experimental servem para avaliar os resultados de políticas de qualificação; os estudos de caso, por sua vez, permitem avaliar a execução destas políticas em objetos mais específicos, como cursos ou instituições; e, ainda, a pesquisa participante visa não apenas gerar conhecimento científico sobre programas e políticas, mas intervir na realidade dos sujeitos envolvidos.

Desta forma, é possível se apreender que todos os procedimentos identificados são funcionais para o tema, porém é necessário que a sua escolha esteja alinhada com os objetivos da pesquisa e com a dimensão do fenômeno que se pretende abordar. 


\section{POLÍTICAS PÚBLICAS E QUALIFICAÇÃO \\ PROFISSIONAL: UMA ANÁLISE DAS \\ METODOLOGIAS DE PESQUISA}

\section{Considerações finais}

Foi objetivo geral deste trabalho analisar metodologias utilizadas em pesquisas nos campos de estudo das políticas públicas de qualificação profissional e da qualificação profissional em turismo. Para isto, foi realizado um levantamento em seis bases de pesquisa que resultou em 45 trabalhos analisados.

Observou-se que, devido a interdisciplinaridade do campo de estudo, a formação dos autores e a área de publicação dos trabalhos abordam mais de dez áreas científicas. O volume da produção apresenta um aumento intermitente com o tempo, consolidando-se a partir de 2013, e os objetos de estudo acompanham o desenvolvimento e a implementação de programas e políticas nacionais de qualificação. As pesquisas contribuem muito para a construção de um histórico das políticas da área e um panorama da diversidade de programas nas regiões brasileiras, todavia a produção é insuficiente sobre avaliação dos resultados dos programas e sobre as ações de qualificação em turismo. Foram também apresentados os principais conceitos relacionados ao campo de estudo, identificados como trabalho, empregabilidade, políticas públicas, educação profissional, qualificação profissional, Estado e políticas públicas. Apesar de se encontrar debates para todos estes conceitos nos artigos analisados, é preciso notar que, com exceção do conceito de qualificação profissional, o debate é relativamente pouco. Um número muito grande de trabalhos aborda discussões sobre políticas públicas e/ou trabalho e renda, porém apenas alguns dedicam-se a discutir estes conceitos e a complexidade destes fenômenos na sociedade atual.

Foram identificados, então, 20 procedimentos metodológicos de pesquisa nos trabalhos analisados, observando-se que, com o passar dos anos, novos procedimentos passam a ser utilizados, enquanto aos já em uso são dadas novas funcionalidades. Cabe reparar que uma parte considerável dos trabalhos não apresenta uma explanação completa ou detalhada das metodologias utilizadas - o que compromete, não apenas a compreensão da pesquisa, mas a integridade de seus resultados. Observa-se, porém, que esta situação é similar a outros campos de pesquisa no turismo. A falta de rigor ou apuração no âmbito metodológico já foi observada na produção científica sobre geografia do turismo (ALBACH, 2015), sobre turismo de base comunitária em Reservas de Desenvolvimento Sustentável (SANTOS; CONTI, 2019) e mesmo na produção de teses e dissertações de programas de pós-graduação em turismo no Brasil (BORGES; MELO; ARAÚJO, 2019).

Embora não seja possível reduzir a aplicação das metodologias a apenas um uso, dentro do âmbito analisado, parte das pesquisas visava debates mais teóricos e conceituais; parte, debruçou-se sobre dados e documentos; bem como outros analisaram a execução prática do fenômeno. Quanto às contribuições para o tema "Políticas públicas de qualificação profissional em turismo", apreendeu-se 


\section{POLÍTICAS PÚBLICAS E QUALIFICAÇÃO \\ PROFISSIONAL: UMA ANÁLISE DAS \\ METODOLOGIAS DE PESQUISA}

que, além desta diferenciação no objetivo de estudo citada, a escolha na dimensão de qualificação que será abordada (educação, trabalho, política) também se relaciona com a escolha da metodologia da pesquisa.

Com o presente estudo, espera-se ter contribuído com a percepção da evolução das pesquisas no campo delimitado - tanto em relação aos objetivos de pesquisa quanto às metodologias utilizadas e demonstrado a amplitude de ferramentas de pesquisa disponíveis para este. Não se pretendeu esgotar o assunto, estando claras as possibilidades de pesquisas alternativas. Esta pesquisa esteve delimitada em seis bases de pesquisa, sendo um complemento importante abordar outras bases, principalmente o Catálogo de Teses e Dissertações. Pesquisas subsequentes podem explorar análises mais específica dos programas nacionais de qualificação, investigações sobre os programas de qualificação em turismo e discussões aprofundadas sobre limites e vantagens de uso de cada metodologia.

\section{Referências}

ALBACH, V. M. A difusão da pesquisa em geografia do turismo na Ibero-América. Tese (doutorado). Universidade Federal do Paraná, Programa de Pós-Graduação em Geografia. Curitiba, 2015. 342f.

AMARO, R. A. Da qualificação à competência deslocamento conceitual e individualização do trabalhador. Revista de Administração Mackenzie, v. 9, n. 7, p. 89-111, nov./dez, 2008.

ARAÚJO, J. P. F.; ANTIGO, M. F. Desemprego e qualificação da mão de obra no Brasil. Revista de Economia Contemporânea, Rio de Janeiro, v. 20, n. 2, p. 308-335, mai/ago, 2016.

ARAÚJO, M. A. D.; BORGES, D. F. Globalização e mercado de trabalho educação e empregabilidade. O\&S, v. 7, n. 17, 2000.

ARAÚJO, T. P.; LIMA, R. A. Formação profissional no Brasil: revisão crítica, estágio atual e perspectivas. Estudos avançados, v. 28, n. 81, 2014.

ASSUNÇÃO, Y. B. Qualificação Profissional ou Competências para o Mercado Futuro. Future Studies Research Journal, São Paulo, v. 8, n. 1, p. 175-207, 2016.

BALESTRO, M. V.; MARINHO, D. N. C.; WALTER, M. I. M. T. Seguro-desemprego no Brasil - a possibilidade de combinar proteção social e melhor funcionamento do mercado de trabalho. Revista Sociedade e Estado, v. 26, n. 2, p. 185-208, 2011.

BARBOSA, R. N. C.; PORFÍRIO, M. I. A qualificação profissional e a Comissão Municipal de Trabalho do Rio de Janeiro. Textos \& Contextos (Porto Alegre), v. 8, n. 2, p. 219-240, 2009.

BORGES, A. L. M.; MELO, M. A. W. S.; ARAÚJO, F. S. G. Técnicas de análise utilizadas em teses e dissertações em turismo. In: EDITORA POISSON (org). Turismo em Foco - Volume 2. Belo Horizonte - MG: Poisson, 2019. p. 88-102. 
BRASIL. Lei $\mathbf{n}^{\mathbf{0}}$ 9.394, de 20 de dezembro de 1996. Estabelece as diretrizes e bases da educação nacional. Brasília, 20 de dezembro de 1996.

BRASIL. MINISTÉRIO DO TURISMO. Plano Nacional do Turismo: diretrizes, metas e programas, 2003 - 2007. Brasília, 29 abr. 2003.

BRASIL. MINISTÉRIO DO TURISMO. Plano Nacional do Turismo: uma viagem de inclusão. 2007 - 2011. Brasília, 2007.

BRASIL. MINISTÉRIO DO TURISMO. Plano Nacional do Turismo: o turismo fazendo muito mais pelo Brasil, 2013 - 2016. Brasília, 2013a.

BULHÕES, M. G. P. Plano Nacional de Qualificação do Trabalhador - Planfor - acertos, limites e desafios vistos do extremo sul. São Paulo Em Perspectiva, v. 18, n. 4, p. 39-49, 2004.

CASSIOLATO, M. C.; GARCIA, R. C. PRONATEC: Múltiplos arranjos e ações para ampliar o acesso à educação profissional, Texto para Discussão, Instituto de Pesquisa Econômica Aplicada (IPEA), No. 1919, 2014.

CATRAMBY, T. C. V; COSTA, S. R. R. Estudo de caso sobre a capacitação docente na área de turismo no estado do Rio de Janeiro. Caderno Virtual de Turismo. v. 5, n. 2, p. 11-28, 2005.

CONCEIÇÃO, R. D. P.; FRAGA, T. F.; CONCEIÇÃO, M. P. Qualificação Profissional - um panorama comparativo entre hotéis e pousadas do primeiro distrito de Petrópolis - RJ. Turismo em Análise, v. 27, n. 1, p. 178-206, 2016.

CORCETTI, E.; LORETO, M. D. S. O discurso político sobre a qualificação profissional de mulheres desfavorecidas - emancipação ou hegemonia. Cadernos EBAPE, v .15, n. 2, p. 364-376, 2017.

CRIVELLARI, H. M. T.; MELO, M. C. O. Saber fazer - implicações da qualificação. Revista de Administração de Empresas, São Paulo, v. 29, n. 2, p. 47-62, 1989.

CHUEKE, G. V.; AMATUCCI, M. O que é bibliometria? Uma introdução ao Fórum. Revista Eletrônica de Negócios Internacionais, v. 10, n. 2, p. 1-5, 2015.

DEITOS, R. A.; LARA, A. M. B. Educação profissional no Brasil - motivos socioeconômicos e ideológicos da política educacional. Revista Brasileira de Educação, v. 21, n. 64, 2016.

DEITOS, R. A.; LARA, A. M. B.; ZANARDINI, I. M. S. Política de educação profissional no Brasil aspectos socioeconômicos e ideológicos para a implantação do Pronatec. Educação e Sociedade, Campinas, v. 36, n. 133, p. 985-1001, out./dez., 2015.

FARIA, V. M; MONTEIRO, M. G. Os canais de participação popular na gestão social um estudo de caso na política nacional de qualificação. Alcance, UNIVALI, v. 11, n. 3, p. 445-459, 2004.

FERREIRA, T. S. Políticas de qualificação profissional no Leste Metropolitano Fluminense, Espaço e Economia, n. 2, p. 1-9, 2013. 
FERRETTI, C. J. Considerações sobre a apropriação das noções de qualificação profissional pelos estudos a respeito das relações entre trabalho e educação. Educação \& Sociedade, Campinas, v. 25, n. 87, p. 401-422, 2004.

FILGUEIRAS, C. A. C. Atores locais na implementação da política de qualificação profissional. Serv. Soc. Soc., São Paulo, n. 107, p. 438-460, 2011.

FRIEDERICH, M.; BENITE, C. R. M.; BENITE, A. M. C. O Programa Nacional de Inclusão de Jovens - Projovem - uma análise entre a proposta oficial e a experiência vivida em Goiânia. Ensaio: aval. pol. públ. Educ., v. 20, n. 74, p. 185-206, 2012.

GARAY, A. B. S. As diferentes faces do processo de qualificação algumas dimensões esquecidas. Revista de Administração, São Paulo, v. 32, n. 3, p. 52-61, 1997.

LEMOS; DUBEUX; PINTO Educação, empregabilidade e mobilidade social - convergências e divergências. Cadernos Ebape, v. 7, n. 2, artigo 8, Rio de Janeiro, 2009.

MELO, F. A. F. Mercado de trabalho flexível e a jovem classe trabalhadora - as políticas de qualificação profissional no plano local. Cadernos CERU, série 2, v. 24, n. 2, 2013.

MANFREDI, S. M. Trabalho, qualificação e competência profissional - das dimensões conceituais e políticas. Educação \& Sociedade, v. 19, n. 64, Campinas, s. p., set. 1999. Disponível em: http://www.scielo.br/scielo.php?script=sci_arttext\&pid=S0101$73301998000300002 \& \operatorname{lng}=$ en\&nrm=iso. Acesso em: 04 out. 2017.

MANFREDI, S. M. Educação Profissional no Brasil: Atores e Cenários ao Longo da História. Paco Editorial, 2016.

MARANHÃO, C. H. S.; BRANDÃO, P. M.; PEQUENO, E. A.; AIRES, J. D. M. Direcionamentos para as Políticas Públicas de Turismo no Rio Grande do Norte, com foco na orientação do Turismo Pró-Pobre. Interface, Natal/RN, v. 7, n. 2, 2010.

MEIRA, C. M.; KUSHANO, E. S.; NEVES, C. S. B. Qualificação profisssional técnica no contexto das políticas públicas de turismo e as novas perspectivas do Plano Nacional de Turismo 2018 - 2022.

Revista Ateliê do Turismo, Campo Grande, v. 1, n. 2. p. 46-66, 2018.

MIRANDA, A. P. R.; ARAÚJO, M. A. D. Transformações no mundo do trabalho um olhar sobre a qualificação profissional. Interface, Natal/RN, v. 3, n. 1, 2006.

MONTALVÃO, L. A. Do PIPMO ao Pronatec - história e atualidade das políticas nacionais de formação da classe trabalhadora. Observatório em Debate, n. 2, p. 2-26, 2015.

MORIN, E. Introdução ao pensamento complexo. Tradução: Eliane Lisboa. Porto Alegre: Sulina, 2006. $120 \mathrm{p}$.

MOURÃO, L. Oportunidades de qualificação profissional no Brasil - reflexões a partir de um panorama quantitativo. RAC, Curitiba, v. 13, n. 1, p. 136-153, 2009.

MUSSE, I.; MACHADO, A. F. Perfil dos indivíduos que cursam educação profissional no Brasil. Economia e Sociedade, Campinas, v. 22, n. 1 (47), p. 237-262, 2013.

Observatório de Inovação do Turismo - Revista Acadêmica

Vol. XIV, n $^{\circ}$, dezembro - 2020 
NASCIMENTO, M. L. O. Pronatec e mundo do trabalho - qualificação profissional para o mercado da informalidade. Revista LABOR, n. 13, v. 1, p. 98-113, 2015.

NOGUEIRA, E. M.; COSTA-NETO, C. P. L.; SILVA, G.P. Qualificação profissional como suporte para implantação do etnoturismo na comunidade indígena Ingarikó (RR). Revista Brasileira de Ecoturismo, v. 6, n. 2, p. 424-441, 2013.

NUNES, M. B. A.; FERNANDES, C. B. Estado, sociedade e políticas de trabalho e emprego voltadas para os jovens no Brasil. Revista Katálysis, v. 19, n. 1, p. 64-72, 2016.

OLIVEIRA, R. Demandas por qualificação profissional - Recife, segunda metade do século XIX.

Revista Brasileira de Educação, v. 18, n. 54, p. 629-646, 2013.

OLIVEIRA, R. Precarização do trabalho - a funcionalidade da educação profissional. Revista Diálogo Educacional, v 15, n. 44, p. 245-266, 2015.

OLIVEIRA, A. M. H C.; RIOS-NETO, E. L. G. Uma Avaliação Experimental dos Impactos da Política de Qualificação Profissional no Brasil. RBE, Rio de Janeiro, v. 61, n. 3, p. 353-378, 2007.

PARENTE, F; MOESCH, M. Desafios das políticas de qualificação para um turismo mais humanizador. Anais do Seminário da ANPTUR. 2016

PEREIRA, P. A. P. Estado, sociedade e esfera pública. Serviço Social: Direitos Sociais e Competências Profissionais. $1^{\text {a }}$ edição. Brasília: CFESS/ABEPSS, 2009. p. 1-18.

PETTERINI, F. C. Uma avaliação econômica do plano setorial de qualificação (planseq). Economia Aplicada, v. 20, n. 3, p. 173-190, 2016.

PICAZO-PERAL, P.; MORENO-GIL, S.; LEÓN-GONZÁLEZ, C. J. Difusión de la investigación científica de turismo en Brasil. Cultur: Revista de Cultura e Turismo, v. 6, n. 4, p. 4-36. 2012

PIMENTEL, T. D.; PAULA, S. C.; OLIVEIRA, M. C. B. Uma reflexão sobre a qualificação na formação em turismo: relevância da micro e pequena empresa para o destino turístico. Turismo y Sociedad, v. 18, p. 159-177, 2016.

PRESTES, E. M. T. A avaliação de políticas sociais - questões teóricas, metodológicas e políticas. Revista Lusófona de Educação, n. 22, p. 85-101, 2012.

PRESTES, E.; VERAS, R. Educação, qualificação, trabalho e políticas públicas - campos em disputas. Revista Lusófona de Educação, n. 14, p. 45-59, 2009.

ROCHA-VIDIGAL, C. B.; VIDIGAL V. G. Investimento na qualificação profissional: uma abordagem econômica sobre sua importância. Acta Scientiarum. Humanand Social Sciences, v. 34, n. 1, p. 41-48, 2012.

SANTOS, G. E. DE O.; REJOWSKI, M. Comunicação científica em turismo no Brasil: Análises descritivas de periódicos nacionais entre 1990 e 2012. Revista Brasileira de Pesquisa em Turismo. São Paulo, v. 7, n.1, p. 149-167, 2013. 
SANTOS, M. L.; CONTI, B. R. Produção científica sobre turismo de base comunitária em Reservas de Desenvolvimento Sustentável (2008-2017): pesquisa bibliográfica e análise das metodologias.

Observatório de Inovação do Turismo - Revista Acadêmica. v. 13, n. 2, p. 100-123, 2019.

SAVIANI, D. O trabalho como princípio educativo frente às novas tecnologias. In: FERRETTI, C. J.; ZIBAS, D. M.; MADEIRA, F. R.; FRANCO, M. L. P. B (org.). Novas tecnologias, trabalho e educação: um debate multidisciplinar. Petrópolis, RJ: Vozes, 1994. p. 151-168.

SENRA, R. E. F.; SATO, M. T.; MELO, G. J.; CAMPOS, A. G. Juventudes, Educação do Campo e Formação Técnica - um estudo de caso no IFMT. Educação \& Realidade, Porto Alegre, v. 42, n. 2, p. 605-626, 2017.

SERRA, R. A política pública de emprego, trabalho e renda no Brasil - estrutura e questões. Revista de Políticas Públicas, v. 13, n. 2, p. 245-254, 2009.

SILVA, A. M. S. Turismo e qualificação profissional - as experiências vivenciadas entre os integrantes da Associação de Condutores de Ecoturismo de Ilha Grande - Piauí-Brasil. Dissertação (mestrado), Universidade Federal do Ceará, Faculdade de Educação, Programa de Pós-Graduação em Educação Brasileira. Fortaleza, 2014, $110 f$.

SILVA, I. C. M. A dimensão política da qualificação profissional na política pública nacional de qualificação profissional em turismo. Dissertação (mestrado), Universidade Federal Fluminense, Programa de Pós-Graduação em Turismo. Niterói, 2019. 262f.

TOMAZONI, E. L. Educação Profissional em Turismo. Cria-se Mercado pela Formação? Turismo em Análise, v. 18, n. 2, p. 197-219, 2007.

TREVISAN, L.; VELOSO, E. Gestão de competitividade e políticas públicas de formação de mão-deobra - O caso Centro Paula Souza. RAP, Rio de Janeiro, v. 41, n. 5, p. 887-908, set./out. 2007.

UNGHERU, B. O.; ISAYAMA, H. F. Os saberes e a formação profissional em lazer - uma análise no campo das políticas públicas. Rev. bras. Estud. pedagog., v. 98, n. 249, p. 389-409, 2017.

VELASCO GONZÁLEZ, M. La política turística. Una arena de acción autónoma. Cuadernos de Turismo, n. 27, p. 953-969, 2011.

VIEIRA, A.; LUZ, T. R. Do saber aos saberes comparando as noções de qualificação e competência. O\&S, v. 12, n. 33, p. 93-108, 2005. 